\title{
A NEW PORTABLE INSTRUMENT TO EVALUATE SOFT FLOORING MATERIALS IN DAIRY COW HOUSING
}

\author{
Paolo Liberati
}

\section{Introduction}

The influence of flooring materials on health, welfare and social behaviour of cows is more and more relevant in dairy housing due to the increasing sensitivity of the high yielding animals to the environment and, in particular, to the walking surfaces. This fact is confirmed by the growing frequency of leg injuries and hoof pathologies occurring in dairy herds.

In recent years several investigations have been carried out on alternative materials and techniques to obtain less hard, slippery and abrasive floors than the common ones made of concrete. In particular, the soft floorings, made of rubber mats, seem to be very interesting according to the results of extensive research showing their beneficial effects on animal health and welfare [Flower 2007; Jungbluth 2003; Vanegas 2006; Vokey 2003].

However the wide variety of products available on the market requires the support of reliable testing techniques to evaluate the effect of each proposed solution on the animal welfare with special reference to skid resistance, being the slipperiness one of the main factors of hoof and leg injuries. To this purpose the friction coefficients, static and dynamic, are the parameters commonly used for a specific evaluation; but the measurement techniques generally adopted in the testing procedures appear to be not very suitable since not capable of reproducing the real interaction between the animal foot and the floor surface [Rushen 2006; Telezhenko 2005; Van der Tol 2005].

With hard floors the friction coefficient is only dependent on the surface characteristics, so that the values are not dependent on the contact pressure exerted by the instrument on the tested material. Considering resilient floors, on the contrary, the penetration of the hoof has a great influence since the skid resistance is

Paper received 23.04.2010; accepted 07.10.2010

Paolo Liberati, Department of Crop Protection and Valorisation (DIPROVAL), University of Bologna, Via f.lli Rosselli 107, 42100 Reggio Emilia, Italy. Tel. 0039.0522.290464 fax 0039.0522.290467 paolo.liberati@unibo.it also dependent on the hoof imprint into the material. So, a separate evaluation of the surface friction and the penetration depth can not be sufficient to reproduce the complex interaction between animal hoof and floor occurring just before and during the sliding movement.

In addition there are no instruments yet available (as far as we know, see also Steiner 2003) capable of making this kind of testing in real housing conditions and with the real load entity. This is a drawback because if such instruments were available it would be possible to assess the variation of the flooring performance through time and in different conditions of use.

For these reasons we decided to carry on a work aimed at realizing an instrument suitable for the measurement of the skid resistance of all kinds of flooring materials capable of evaluating the combined effect of the surface texture and the deformability of the materials, being also portable and suitable for specific tests in real housing conditions. The functioning of the instrument and the results of laboratory tests are presented in this paper. Also the first field test results are shown.

\section{Materials and Methods}

The instrument (Fig. 1), in the following called Flooring Material Properties Instrument (FMPI), based on the drag method, consists of the following parts (Fig. 2): a) a device (coil spring) capable of exerting a vertical force up to $250 \mathrm{daN}$; b) a test body in the shape of a claw $\left(60 \mathrm{~cm}^{2}\right)$, made of polypropylene, set on a sled; c) a pushing device capable of exerting a horizontal force and moving the sled at a constant speed; d) a system of sensors and load cells measuring various parameters (vertical and horizontal force, tilting angle, penetration of the test body into the sample material).

The ratio of the horizontal limit force (immediately before the claw displacement) to the vertical force gives the static coefficient of friction (COF). The same ratio during the movement represents a sort of dynamic COF, variable with the decrease of the verti- 


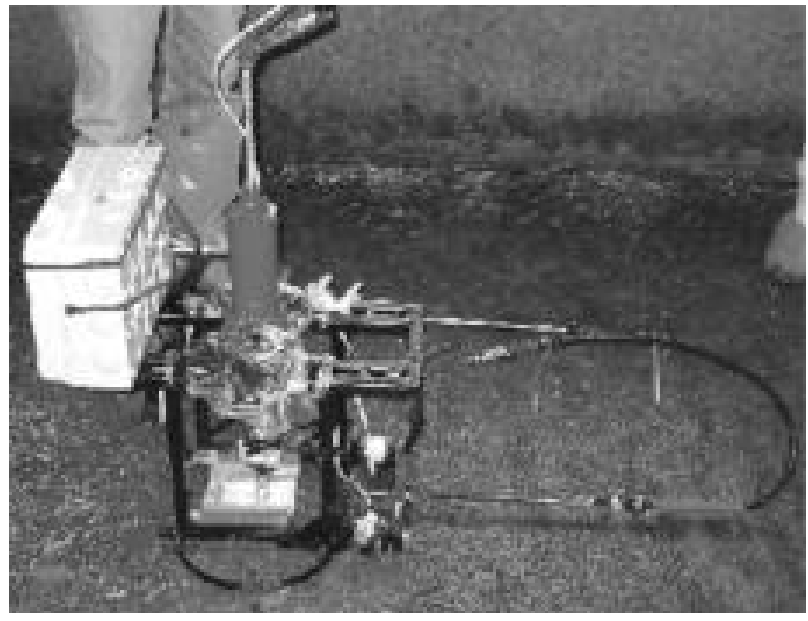

Fig. 1 - The new portable instrument during a test in the feeding alley.

cal force. This is not exactly what is commonly called dynamic COF, but it can well indicate the reaction of the floor to the hoof continuously slipping, while the load is progressively transferred to the other feet.

So we can observe the pattern of the vertical and horizontal forces during the cow displacement. In fig. 3 the same pattern as recorded by means of a platform equipped with tri-axial load cell is reported [Webb 1981].

In the first laboratory trials nine commercial flooring materials were tested, eight rubber mats, with or without burls on the bottom side, and one highly abrasive hard floor made of an epoxy resin coat with coarse aggregates on a concrete base. When burls are not present in the bottom side, grooves are present (see Fig. 4, middle column). Testing laboratory conditions were: 1) clean and dry floors; 2) floors covered with wetted clay (to simulate a real dirty floor).

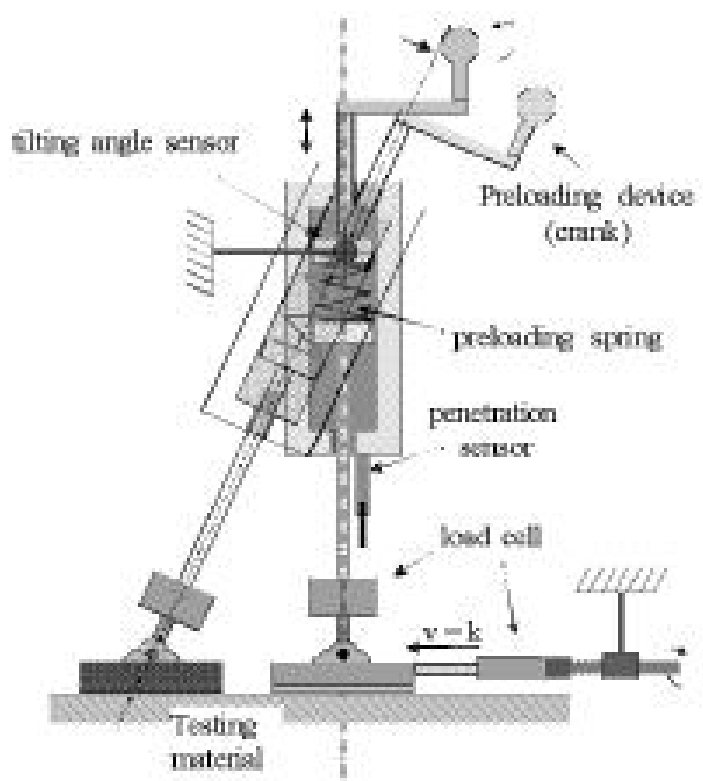

Fig. 2 - Scheme of the instrument used to asses the flooring material properties (FMPI)
In a second step, field tests were conducted in real conditions on four different floor materials: three mats (B, C, F), and a Resin. Furthermore, the concrete floorings of the feeding alley in two barns were tested too.

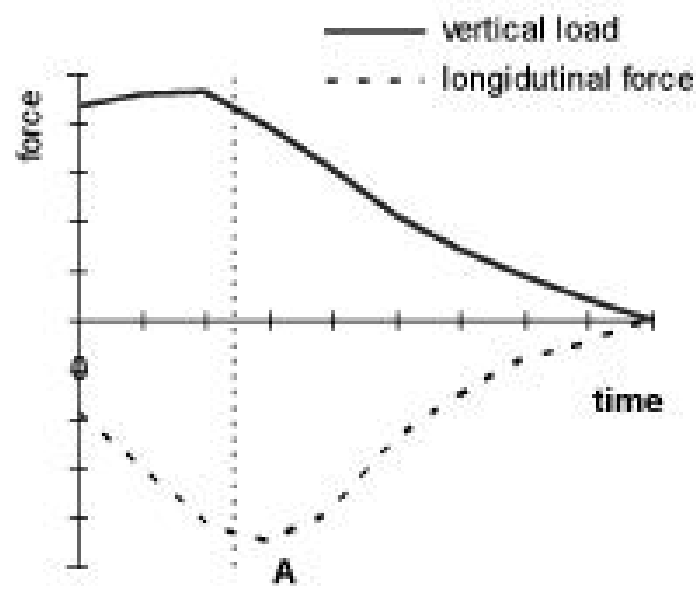

Fig. 3 - Recorded reaction forces of the rear foot by means of a triaxial weighing platform during cow displacement (from Webb and Clark).

The main parameters obtained directly from the FMPI test are: static coefficient of friction (COF) (S_COF, the maximum COF before sled starts its displacement); sinking depth of the claw in the floor (sinking in $\mathrm{mm}$ and $\%$ on total thickness). This parameter is recorded after the loading procedure ends. Other calculated parameters are: I_COF10, the integral of the COF for the first 10 rotation degrees of the loading jack (the maximum rotation angle is $40 \mathrm{de}-$ grees). It represents a sort of dynamic COF measured during the sled movement with a varying load; the Integral of the pushing force (IPF) to the time divided by the total time, calculated as the integral of the horizontal force for the whole test (or until probe escaping). The measuring unit of IPF is in N.

Furthermore, conventional tests were carried out to calculate the dynamic COF (so called D_COF) pulling the sled through the FMPI in a changed configuration (the pushing device is used in a reverse mode to pull the sled, loaded with a ballast of $60 \mathrm{~N}$ ).

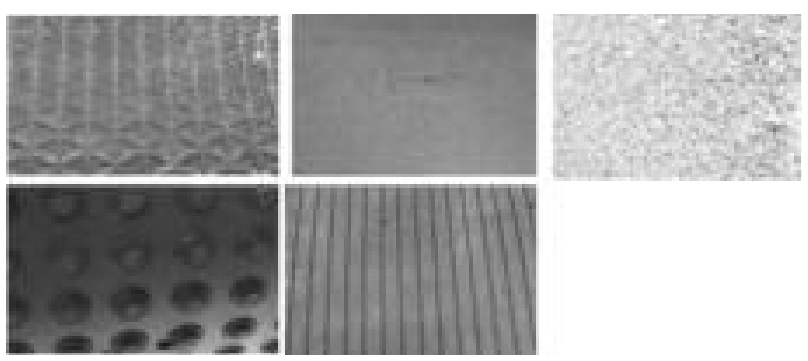

Fig. 4 - Top and bottom view of three tested materials: on the left, rubber mat with burls; in the middle, mat with grooved bottom side; on the right the resin coat. 


\begin{tabular}{cccccc}
\hline $\begin{array}{c}\text { floor } \\
\text { type }\end{array}$ & $\begin{array}{c}\text { total trickness } \\
\text { (mm) }\end{array}$ & $\begin{array}{c}\text { rubber height } \\
\text { (mm) }\end{array}$ & $\begin{array}{c}\text { but height or depth } \\
\text { of the groove (mm) }\end{array}$ & $\begin{array}{c}\text { burvtotal height } \\
\text { ratio }\end{array}$ & $\begin{array}{c}\text { burts or } \\
\text { groowes (BG) }\end{array}$ \\
\hline A & 18.0 & 13.5 & 4.5 & 0.25 & B \\
B & 23.0 & 18.0 & 5.0 & 0.22 & B \\
C & 19.5 & 15.0 & 4.5 & 0.23 & B \\
D & 17.0 & 13.0 & 4.0 & 0.24 & G \\
E & 12.0 & 9.5 & 2.5 & 0.21 & G \\
F & 17.5 & 12.5 & 5.0 & 0.29 & G \\
G & 18.5 & 13.5 & 5.0 & 0.27 & B \\
H & 27.0 & 14.5 & 12.5 & 0.46 & B \\
RESIN & 5.0 & - & - & - & - \\
\hline
\end{tabular}

1) Indcative value

TABLE 1 - Main characteristics of the tested materials.

In Table1 some characteristics of the examined flooring materials are reported, while in Figure 4 the pictures of three samples are presented.

\section{Results and discussion}

In Table 2 the results of the laboratory and field tests (only for floors B, C, F, and RESIN) are presented. In housing conditions two concrete floors have been tested too.
The patterns of the vertical and horizontal forces are shown in Figure 5 as recorded during the field tests for the concrete floor and rubber floor $\mathrm{F}$ in feeding alleys. In Fig. $6 \mathrm{COF}$ values are presented as calculated from the data of Figure 5. In field tests floor surface is covered with cow manure. In the case of concrete floors, the probe, after a displacement of about $9 \mathrm{~cm}$, lost the contact with the floor surface resulting in a rapid slipping, here called foot escape.

In Table 2, S_COFclean reveals that it is not adequate to characterize the very slippery floors (those

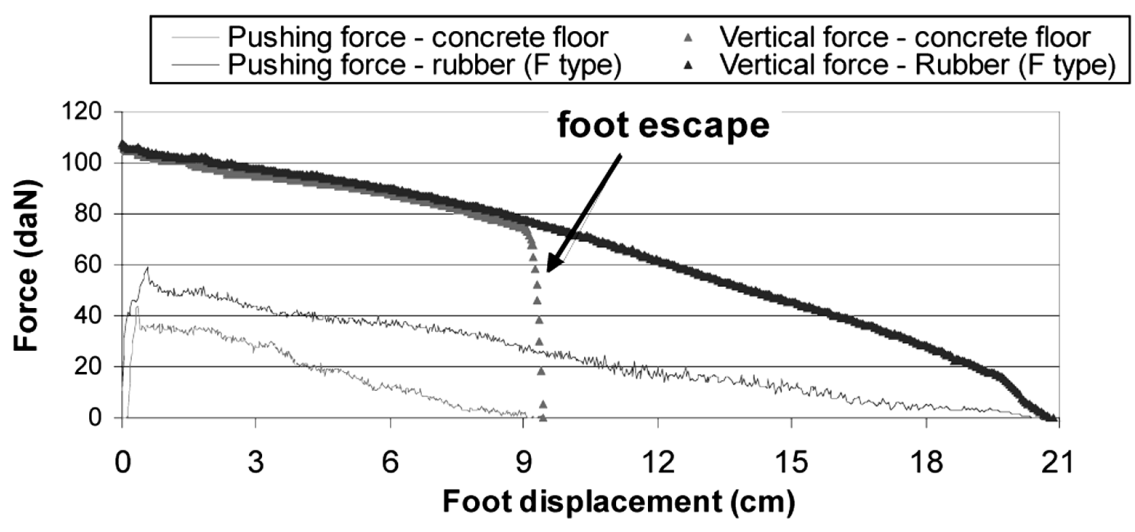

Fig. 5 - Vertical and pushing forces in field tests.

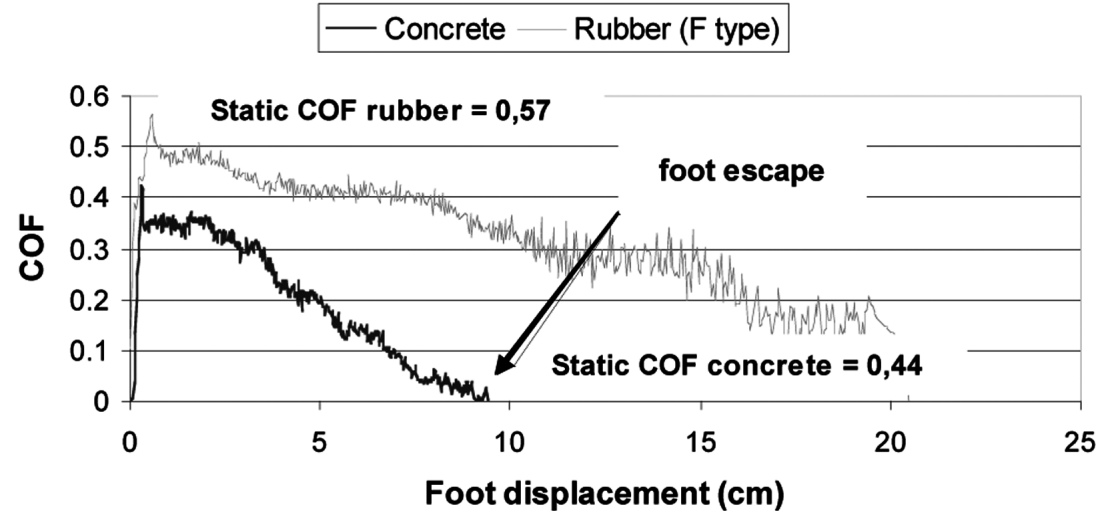

Fig. 6 - Calculated COF for the same tests in fig. 5. 


\begin{tabular}{|c|c|c|c|c|c|c|c|c|c|c|c|}
\hline \multirow[b]{2}{*}{ Flooring mat } & \multirow{2}{*}{$\underset{\text { clean }}{\text { S_COF }}$} & \multirow{2}{*}{$\begin{array}{l}\text { D_COF } \\
\text { (clean) }\end{array}$} & \multicolumn{2}{|c|}{ S_COF dirty } & \multicolumn{2}{|c|}{ I_COF10 dirty } & \multicolumn{2}{|c|}{$\operatorname{IPF}(\mathrm{N})$} & \multirow{2}{*}{$\begin{array}{c}\text { Sinking } \\
(\mathrm{mm})\end{array}$} & \multirow[b]{2}{*}{ Sinking (\%) } & \multirow{2}{*}{$\begin{array}{l}\text { Foot } \\
\text { escape }\end{array}$} \\
\hline & & & $\begin{array}{l}\text { lab.test } \\
\text { (clay) }\end{array}$ & $\begin{array}{l}\text { Field test }{ }^{1} \\
\text { (manure) }\end{array}$ & $\begin{array}{c}\text { lab.test } \\
\text { (clay) }\end{array}$ & $\begin{array}{l}\text { Field test } \\
\text { (manure) }\end{array}$ & $\begin{array}{l}\text { lab.test } \\
\text { (clay) }\end{array}$ & $\begin{array}{l}\text { Field test } \\
\text { (manure) }\end{array}$ & & & \\
\hline$A$ & 0.78 & 0.65 & 0.39 & -- & 0.16 & -- & 22.5 & -- & 3.4 & 18.6 & No \\
\hline B & 0.48 & 0.61 & 0.35 & 0.50 & 0.21 & 0.41 & 25.7 & 29.3 & 2.3 & 9.9 & No \\
\hline $\mathrm{C}$ & 0.68 & 1.06 & 0.37 & 0.47 & 0.20 & 0.37 & 25.3 & 27.4 & 3.7 & 18.8 & No \\
\hline $\mathrm{D}$ & 0.60 & 0.55 & 0.36 & -- & 0.15 & -- & 17.4 & -- & 2.4 & 14.2 & Yes \\
\hline$E$ & 0.74 & 0.48 & 0.37 & -- & 0.14 & -- & 15.4 & -- & 1.4 & 11.3 & Yes \\
\hline $\mathrm{F}$ & 0.63 & 1.10 & 0.39 & 0.57 & 0.23 & 0.45 & 34.4 & 33.7 & 1.8 & 10.1 & No \\
\hline $\mathrm{G}$ & 0.58 & 1.07 & 0.36 & -- & 0.17 & -- & 21.6 & -- & 3.1 & 16.5 & Yes \\
\hline $\mathrm{H}$ & 0.61 & 0.91 & 0.36 & -- & 0.20 & -- & 26.3 & -- & 3.8 & 14.1 & No \\
\hline RESIN & 0.51 & 0.48 & 0.44 & 0.42 & 0.25 & 0.25 & 22.3 & 21.6 & 0.6 & -- & Yes \\
\hline Concrete_A & -- & -- & -- & 0.37 & -- & 0.22 & -- & 15.5 & 0.5 & -- & Yes \\
\hline Concrete_B & -- & -- & -- & 0.44 & -- & 0.28 & -- & 21.3 & 0.6 & -- & Yes \\
\hline
\end{tabular}

1) Field tests are intended with manure in the feeding alley

TABLE 2 - Laboratory tests on nine commercial mats and field tests on two concrete floors. S_COF = the maximum COF; Sinking $\mathrm{mm}=$ sinking depth of the claw in the floor after the loading procedure ended; sinking $\%=$ sinking depth, $\%$ on total thickness; I_COF10 $=$ integral of the COF for the first 10 rotation degrees of the loading jack; IPF = Integral of the pushing force to the time divided by the total time for the whole test (or until probe escaping); D_COF = conventional dynamic COF (sled loaded with a ballast of $60 \mathrm{~N}$ ).

\begin{tabular}{c|ccccccc} 
& \multicolumn{2}{|c}{ Sinking mm Sinking \% } & D_COF & BTR & IPF & BG & thickness \\
\hline Sinking mm & $\mathbf{1 . 0 0}$ & 0.78 & 0.41 & 0.49 & 0.13 & 0.80 & 0.65 \\
Sinking \% & 0.78 & $\mathbf{1 . 0 0}$ & 0.26 & 0.01 & -0.22 & 0.54 & 0.05 \\
D_COF & 0.41 & 0.26 & $\mathbf{1 . 0 0}$ & 0.38 & 0.69 & 0.30 & 0.32 \\
BTR & 0.49 & 0.01 & 0.38 & $\mathbf{1 . 0 0}$ & 0.38 & 0.25 & 0.71 \\
IPF & 0.13 & -0.22 & 0.69 & 0.38 & $\mathbf{1 . 0 0}$ & 0.17 & 0.48 \\
BG & 0.80 & 0.54 & 0.30 & 0.25 & 0.17 & $\mathbf{1 . 0 0}$ & 0.67 \\
thickness & 0.65 & 0.05 & 0.32 & 0.71 & 0.48 & 0.67 & $\mathbf{1 . 0 0}$
\end{tabular}

TABLE 3 - Correlation table.

with foot escape D, E, G, and RESIN): in fact we would have expected always lower values for more slippery floors, but it is not true for floors D and RESIN. For example, floor E presents a foot escape although has a $S_{-}$COFclean much higher than floor B (0.74 and 0.48 respectively). When wetted clay was added $S \_C O F$ became similar for all the floor mats, except for RESIN. The parameter D_COF could be better representative because more slippery floors have lower values, except for floor $\mathrm{G}$ with the second highest value. I_COF10 is a good parameter to discriminate the slipperiness level of floors, but even better is the parameter $I P F$. This parameter discriminates correctly among the floors with foot escape and the other, included the RESIN. At first indication we can say that slipping can happen with a IPF value lower than $22.3 \mathrm{~N}$.

Again in Table 2, we can see that concrete floors which in the field tests present a strong slipperiness have $I P F$ values lower than the discriminating threshold of $22.3 \mathrm{~N}$ above proposed: 15.5 and $21.3 \mathrm{~N}$ respectively for A and B floors.

Foot escape depends not only on insufficient $S \_C O F$, but also on the residual friction reaction of the floor after foot sliding is started. This aspect is well represented by the $I P F$ parameter.

Comparing the laboratory test and the field test (possible only for B, C, F, and RESIN mats) we can see that $I P F$ shows a good correspondence. Whilst if we compare $S \_C O F$ using clay in lab. tests and manure in field tests, we can see that clay acts more as a lubricant than as manure.

From Table 3, the parameter IPF does not seem to have a direct correlation with hoof sinking $(r=0.13)$. There is a better correspondence considering the ratio of burl height to the total thickness $(B T R, \mathrm{r}=0.38)$. Good correlations show $D C O F(\mathrm{r}=0.69)$ and thickness $(r=0.48)$. In the attempt to correctly estimate the real contribution of each parameter to the independent variable $I P F$, we did a statistical multiple regression. The first step was to evaluate the multicollinearity among the independent variables to be included in the model:

$$
\begin{gathered}
I P F=\mathrm{f}\left(D \_C O F, \text { sinking, sinking\% } \%, \text { thickness },\right. \\
B T R, B G)
\end{gathered}
$$

Where:

$I P F=$ integral of the horizontal force;

$D \_C O F=$ conventional dynamic coeff. of friction with fixed load;

$B T R=$ burl height by total thickness ratio;

$B G=$ presence of burls or groove in the bottom side;

Sinking, sinking depth in $\mathrm{mm}$, sinking\% = sinking depth in \% of thickness;

thickness $=$ overall thickness . 


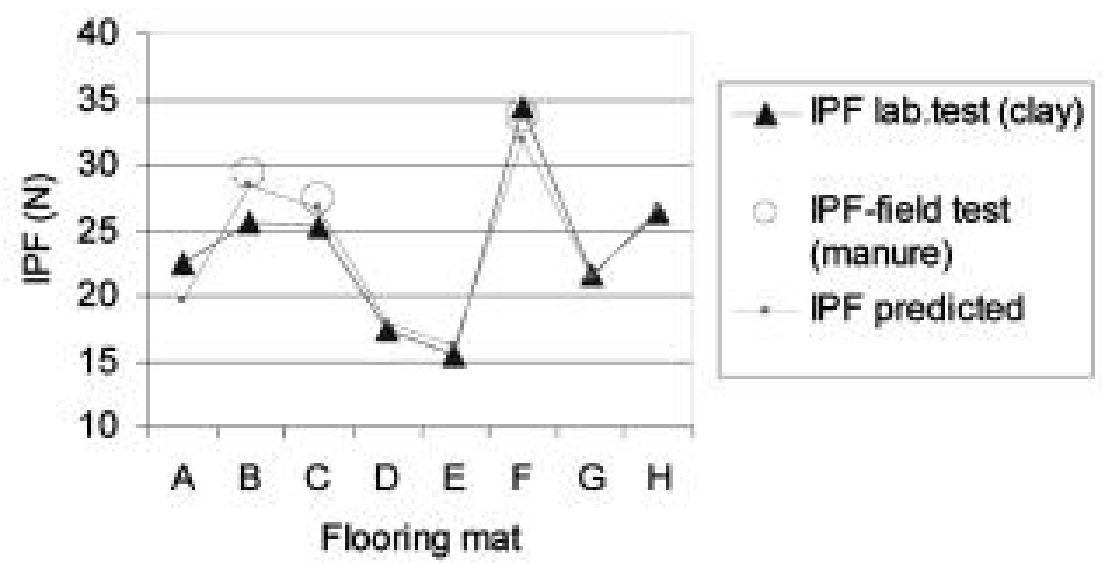

Fig. 7 - Comparison of the regression model with lab. and field test data.

The first three variables in tab. 4 can be considered independent (tolerance $>0.1$ and variance inflation factor $\mathrm{VIF}<10$ ).

\begin{tabular}{lcc}
\hline \multicolumn{1}{c}{ Variable } & Tolerance & VIF \\
\hline D_COF & 0.509 & 2.0 \\
BG & 0.210 & 4.8 \\
BTR & 0.143 & 7.0 \\
thikness & 0.008 & 122.2 \\
Sinking\% & 0.004 & 234.5 \\
Sinking $(\mathrm{mm})$ & 0.002 & 400.1 \\
\hline
\end{tabular}

TABLE 4 - Multicollinearity tests for the global model (VIF $=$ variance inflation factor).

The multiple linear regression with these variables shows that these variables are independent, but only the regression coefficient of $D_{-}$COF can be considered significant (see Tab. 5, p-value $=0.005$ ). At this point we furthermore reduce the model considering only $D \_C O F$ :

$$
I P F=\alpha \times D \_C O F+\text { constant }
$$

This model presents an adjusted $\mathrm{R}$ square of 0.883 , significant at $\mathrm{p}<0.05$.

\begin{tabular}{cccc}
\hline Variable & Tolerance & VIF & p-value \\
\hline$D \_C O F$ & 0.858 & 1.17 & 0.005 \\
$B G$ & 0.910 & 1.10 & 0.650 \\
$B T R$ & 0.852 & 1.17 & 0.663 \\
\hline
\end{tabular}

TABLE 5 - Multicollinearity tests and significance level for the reduced model.

In Figure 7 the comparison of the regression model applied to laboratory and field test data is presented. Predicted values are in close agreement with meas- ured values, less for the first three mats. Always in Figure 7 we can also appreciate the very close agreement of the model with the results in field tests (only for $\mathrm{B}, \mathrm{C}$ and $\mathrm{F}$ flooring mats). Then, the high contribution in the model of $D_{-} C O F$ is in accordance with the relevance of the superficial texture of the floor. Instead, the absence of the sinking parameters appears quite strange (that is the softness of the floor) in the final model.

\section{Conclusions}

The first trials showed a good performance of the experimental instrument and, especially, a good capability of appreciating the performance of the softer materials in farming conditions thanks to a more similar behaviour to the real foot biomechanics than the common laboratory instruments. This fact is due to the possibility of determining the static COF under vertical forces as great as those exerted by the animal hoof on the floor, and also due to highlighting the material performance during the foot sliding movement.

In addition the instrument is portable and designed to be suitable for tests in any use conditions. To this purpose a specific calibration is required to ascertain whether a reduction of the vertical load can be applied, to facilitate its practical use, following a reduction of the test body dimensions.

Further field trials will identify the efficiency and reliability of the instrument in real housing conditions and permit to appreciate the effect of the indicated parameters on animal welfare and health.

\section{References}

Flower F.C., De Passilé A.M., Weary D.M., Sanderson D.J., Rushen J., Softer, Higher-Friction Flooring Improves Gait Of Cows With And Without Sole Ulcers. J. Dairy Sci. ( 2007) 90:1235-1242.

Jungbluth T., Benz B., Wandel H., Soft Walking Areas In Loose Housing Systems For Dairy Cows. Proc. Fifth Int. 
Dairy Housing Conference, 29-31 January, Fort Worth, Texas. (2003) 171-177.

Philips C.J.C. and Morris D.I., The Locomotion Of Dairy Cows On Concrete Floors That Are Dry, Wet, Or Covered With A Slurry Of Excreta. J. Dairy Sci. (2000) 83:1767-1772.

Rushen J. and De Passilé A.M., Effects Of Roughness And Compressibility Of Flooring An Cow Locomotion. J. Dairy Sci. (2006) 89: 2965-2972.

Steiner B. and Van Caenegem L., Comment Mettre En Place Des Voies De Circulation Plus Respectueuses Des Animaux Dans Les Étables?. (2003) Rapport Fat N. 594/2003. 1-13.

Telezhenko E. and Bergsten C., Influence Of Floor Type On The Locomotion Of Dairy Cows. Appl. Anim. Behav. Sci. (2005) 93: 183-197.

Telezhenko E., Bergsten C., Magnusson M., Ventrop M., Nilsson C., Effect Of Different Flooring Systems In Weight And Pressure Distribution On Claws Of Dairy Cows. J. Dairy Sci. (2008) 91:1874-1884.

Van Der Tol P.P.J., Metz J.H.M., Noordhuizen-Stassen E.N., Back W., Braam C.R., Weijs W.A., Frictional Forces Required For Unrestrained Locomotion In Dairy Cattle. J. Dairy Sci. (2005) 88: 615-624.

Vanegas J., Overton M., Berry S.L., Sischo W.M., Effect Of Rubber Flooring On Claw Health In Lactating Dairy Cows Housed In Free-Stall Barns. J. Dairy Sci. (2006) 89:4251-4258.

Vokey F.J., Guard C.L., Erb H.N., Galton D.M., Observation On Flooring And Stall Surfaces For Dairy Cattle Housed In A Free-Stall Barn. Proc. Fifth Int. Dairy Housing Conference, 29-31 January, Fort Worth, Texas. (2003) 165-170.

Webb N.G. and Clark M., Livestock Foot-Floor Interactions Measured By Force And Pressure Plate. Farm Building Progress. (1981) 66, 23-6.

\section{SUMMARY}

The improvement of flooring materials performance on animal health and welfare requires the support of reliable testing techniques. This is particularly relevant with the synthetic soft coverings used for walking areas since the friction coefficient is not only dependent on the surface characteristics, but also on the penetration of the animal hoof into the material.

The paper presents the functioning of a new instrument capable of reproducing more closely the real interaction between the floor surface and the animal foot. The instrument is simple and portable and is suitable both for laboratory measurements and real housing conditions.

The measurement is made in two steps: first a probe, shaped as a cow hoof and contacting the testing floor surface, is loaded with a vertical force to obtain a pressure similar to that exerted by the animal; then a pushing force parallel to the floor is applied, at a constant speed, producing a displacement along the surface. The values of the vertical and horizontal strengths required for skidding and the angle of the instrument are continuously measured and by them various parameters can be calculated.

The results of the tests carried out in the laboratory and in real dairy houses are presented and, through the analysis of various calculated physical parameters, the main floor properties - more suitable for a previous estimate of the effect on animal welfare - are determined and discussed.

In particular, the IPF parameter has been the only one able to predict also the foot escape among all the considered parameters.

Keywords: Dairy cows, Floors, Test instrumentation. 